\title{
A EXTENSÃO ACADÊMICA COMO FERRAMENTA PARA APRENDIZAGEM NO ENSINO SUPERIOR
}

\author{
G. B. DE L. DE FARIAS ${ }^{1}$, R. S. RODRIGUES ${ }^{2}$ e S. R. P. CARDOSO ${ }^{3}$ \\ Instituto Federal de Educação, Ciência e Tecnologia do Pará \\ glorgia_farias@hotmail.com
}

Artigo submetido em 04/11/2019 e aceito em 18/12/2019

DOI: $10.15628 /$ holos.2019.9133

\section{RESUMO}

A extensão acadêmica no Brasil é apresentada atualmente como um instrumento utilizado pelas Instituições de Ensino Superior visando a realização do seu compromisso social, em que há troca de conhecimento com a sociedade, ou seja, um diálogo de saberes. Diante disso, o objetivo deste artigo é analisar a relação entre os projetos de extensão acadêmica e a formação profissional dos alunos do curso superior de tecnologia em gestão ambiental. Tendo como perspectiva a análise de conteúdo, foram realizadas, além de pesquisas bibliográficas e entrevistas; após a coleta de dados, implementou-se a análise de conteúdo propriamente dita a fim de identificar e discutir os pontos mais relevantes entre as atividades de extensão e o processo de ensino e aprendizagem no referido curso. Como desfecho desta pesquisa, destaca-se que, mesmo com limitações, a extensão acadêmica contribuiu para a formação do aluno, pois é notório uma maior integração entre os saberes da academia e os saberes advindos das comunidades parceiras, o que proporcionou aos sujeitos envolvidos a formação não apenas técnica do profissional, mas de um ser humano por inteiro e suas mais diversas dimensões (social, política, econômica, humana, entre outras).

PALAVRAS-CHAVE: Extensão Universitária, Formação Profissional, Gestão Ambiental.

\section{ACADEMIC EXTENSION AS A TOOL FOR LEARNING IN HIGHER EDUCATION}

\begin{abstract}
The academic extension in Brazil is currently updated as an instrument used by Higher Education Institutions that use the realization of their social commitment, in which there is exchange of knowledge with society, that is, a dialogue of saber. Given this, the objective of this article is to analyze the relationship between academic extension projects and the professional education of students in environmental management technology. With a content analysis perspective, bibliographic research and interviews were conducted; After collecting
\end{abstract}

data, implement appropriate content analysis to identify and discuss the most relevant points between extension activities and the teaching and learning process in the indicated course., even with limited permissions, with academic extension for student training, as this is a feature of greater integration between academy students and advanced students from partner communities, or has offered participants involved in not only technical but also a whole human being and its various dimensions (social, political, economic, human, among others).

KEYWORDS: University Extension, Vocational Training, Environmental Management. 


\section{INTRODUÇÃO}

A atividade extensionista promovida por instituições de ensino superior, segundo Nogueira (2005) e Rodrigues (2013), surge a partir do século XIX na Inglaterra, com a proposição de educação continuada e destinada à população adulta que não se encontrava nas universidades ou não tinha acesso a elas. A partir desse modelo de iniciativa Inglês, o Brasil inicia sua incursão pela implantação da extensão universitária. No Brasil, tais atividades também obtiveram influências do modelo de extensão empregado nas universidades dos Estados Unidos - EUA. Este binômio metodológico tinha suas particularidades, onde o modelo inglês influenciou nos cursos e o modelo EUA na forma de prestação do serviço de extensão.

É perceptível, então, que a extensão acadêmica no Brasil se consolida em modelos importados, que não retratam ou se adéquam à realidade local, e se presume que poucas ou nenhuma das ações de extensão universitária são colocadas em prática no país; talvez seja pelos modelos copiados, que se baseiam na essência cultural e educacional dos países de origem.

De acordo com Mendonça et al (2013), a extensão acadêmica no Brasil era concebida na década de 1930 como um espaço para a realização de cursos e conferências, que objetivavam difundir conhecimento para a sociedade. Entretanto, a partir de 1980, os projetos de extensão passam a ser realizados num cenário de diálogo entre os saberes da academia e os saberes empíricos da sociedade fora da academia, e nesse momento o conceito de extensão começa a ser percebido com a perspectiva de integração entre academia e comunidade, e não mais, somente, como prestação de serviço ou transmissão de conhecimento acadêmico para a população, como se apenas os saberes acadêmicos fossem verdadeiros e válidos.

Atualmente, a extensão é apresentada como um instrumento utilizado pelas instituições de ensino superior, que visa à realização do seu compromisso social; no entanto, numa via de mão dupla, em que há troca de conhecimento por ambas as partes (RODRIGUES, 2013).

Tal conceito, porém, ainda sofre algumas distorções por muitos docentes e estudantes, bem como a indissociabilidade entre pesquisa, ensino e extensão. $E$, como consequência dessa dificuldade de definição do que é de fato a extensão, observa-se hoje o desenvolvimento de projetos de extensão que na realidade não se enquadram como tal.

Nesse sentido, Jesine (2004) levanta uma discussão em que destaca a existência de três vertentes de ações extensionistas: a concepção assistencialista, a acadêmica e a mercantilista. A primeira, pode-se dizer que é aquela pautada no atendimento às demandas sociais através da prestação de serviços e resolução de problemas sociais. A segunda se caracteriza pela função acadêmica da universidade, em que essa tem a função de levar o conhecimento para além dos muros institucionais. Por fim a concepção mercantilista, que de acordo com a autora, vem se formando a partir das mudanças do Estado e da sociedade, e também na busca pela valorização de sua função acadêmica no mesmo nível que a do ensino e da pesquisa, sendo que a parceria ou a venda de serviços seria o meio (frente aos desafios da escassez de auxílios financeiros e fomentos) para articular a academia com os demais setores da sociedade. 
Os poucos esforços em se desenvolver projetos de extensão esbarram em problemas tais como: a natureza interdisciplinar, a realização de atividades além das salas de aulas e dos laboratórios, o fato de ser voltada para o atendimento de um público amplo, difuso e heterogêneo (PAULA, 2013).

Mediante as questões supracitadas, este artigo surge a partir da seguinte problemática;

- $\quad$ Em que medida os projetos de extensão desenvolvidos no curso de Tecnologia em Gestão Ambiental do IFPA - Campus Bragança contribuem (ou não) para a formação profissional de seus discentes?

Dessa forma, a pesquisa possibilita compreender a visão do discente acerca da extensão acadêmica e a influência da mesma sobre sua formação e futura atuação profissional. Ademais, viabiliza a discussão acerca das limitações existentes na prática extensionista, bem como evidencia suas potencialidades. Compreender a relação entre os projetos de extensão e a formação dos discentes se mostra fundamental para o desenvolvimento de um processo de reestruturação das atividades, que possibilite o aprimoramento das técnicas e materiais utilizados; o fortalecimento da extensão nas instituições de ensino, de modo a aproximar a comunidade da academia; e para o aumento da prática de atividades de extensão em instituições de ensino superior.

Nesse sentido, este artigo objetiva investigar a relação existente entre os projetos de extensão a formação profissional dos discentes do curso superior de Tecnologia em Gestão Ambiental do IFPA Campus Bragança.

Mais especificamente, busca-se: identificar os pontos positivos e negativos do desenvolvimento de projetos de extensão para a formação dos alunos; evidenciar como os alunos envolvidos com projetos de extensão universitária percebem sua atuação e desenvolvimento profissional através destas práticas; e analisar qualitativamente a utilização das atividades de extensão como ferramenta para aprendizagem no ensino superior.

\section{IMPORTÂNCIA DA EXTENSÃO ACADÊMICA}

A extensão acadêmica faz parte do tripé ensino-pesquisa-extensão, que sustenta os objetivos das instituições de ensino superior. Por isso, a extensão não deve ser colocada à parte, nem ter 'menos valor' para a comunidade acadêmica, pois é através da extensão que a comunidade externa à academia tem contato com o que é aprendido e produzido pela mesma.

Através da extensão, também, a comunidade pode usufruir de benefícios oriundos do conhecimento desenvolvido na academia, participando de aperfeiçoamentos em processos produtivos, utilizando novas tecnologias e adquirindo conhecimento em diversas áreas através cursos e oficinas. Dessa forma, a extensão pode ser definida como um processo social e de ação cidadã, em que a sociedade também é sujeito de conhecimento, de saberes e de práticas que ao interagirem com o saber científico, se potencializam (MARINHO, et al, 2018).

Nesse sentido, a extensão em nível local, se apresenta como uma ferramenta importante para a disseminação das informações relacionadas com a temática ambiental, em que as informações teóricas aprendidas em sala de aula sejam colocadas em prática (CHIMINAZZO et al, 
2018). Ou seja, a extensão compreende a produção, a validação, a valorização, a experimentação e a troca de conhecimentos entre a Universidade e a sociedade (MARINHO, et al, 2018).

E esta troca de conhecimentos é algo fundamental para o aluno extensionista, pois a ele é dada a oportunidade de ensinar e aprender. Ensinar aquilo que aprende em sala de aula, nos laboratórios, nos debates acadêmicos; e aprender com a população, com o público alvo do projeto de extensão, os quais, embora muitas vezes não tenham o conhecimento técnico, detém o conhecimento tradicional, necessário para adaptar a técnica às demandas da comunidade. Ensinar é uma forma extraordinária de aprendizagem e de fixação de conhecimento. Dar aulas é aprender sobre $o$ assunto de maneira permanente.

De acordo com Freire (1996), é necessário que o trabalho educacional parta da realidade, possibilitando assim o diálogo e a reflexão com suporte na relação existente entre a teoria e a prática. Ensinar não corresponde à mera 'transmissão do conhecimento', mas sim à criação de possibilidades para sua produção ou sua construção.

Conforme destaca Freire (2018), o que o extensionista busca é estender seus conhecimentos e suas técnicas, porém deve ir além, ou seja, a extensão "não deve negar a ação e a reflexão verdadeiras àqueles que são objetos de tais ações". Deve, portanto, dar a possibilidade de aperfeiçoamento das técnicas à comunidade, considerando as particularidades locais, sociais, culturais e ambientais.

Para Moita e Andrade (2009), "ainda se produz um conhecimento desligado das necessidades populares cotidianas", ou seja, pela característica de grande parte das universidades brasileiras, e pelo perfil dos profissionais ali presentes, há uma priorização da produção do conhecimento direcionada para periódicos de primeira linha em detrimento das necessidades diárias da comunidade.

É necessário que a comunidade acadêmica considere em equivalência de patamares a extensão e a produção intelectual para publicações científicas. Isso pode resultar em mais impacto da academia na sociedade, a qual tem mais possibilidade de se apropriar do conhecimento produzido e, mais importante, construí-lo em conjunto. Além disso, é mais provável que a sociedade defenda, pelos benefícios citados, a permanência e o fortalecimento das instituições de ensino.

\section{METODOLOGIA}

\subsection{Princípio Metodológico}

O princípio metodológico aplicado é o da Pesquisa-Ação, que corresponde a uma pesquisa participante engajada, que busca unir pesquisa e ação ou prática (ENGEL, 2000). É uma estratégia que visa o desenvolvimento de professores e pesquisadores, para que estes possam utilizar suas pesquisas para aprimorar o seu ensino e consequentemente o aprendizado de seus alunos. Nesse sentido, segue um ciclo que compreende o planejamento, a implementação, a descrição e a avaliação de uma mudança para a melhora da prática; com isso ocorre um aprendizado no decorrer do processo (TRIPP, 2005). 


\subsection{Local de Pesquisa}

A pesquisa foi realizada no município de Bragança, que pertence à mesorregião do Nordeste Paraense e à microrregião Bragantina. É apresentando como recorte espacial para a sede do município, a qual margeia o Rio Caeté, e com foco especial no Instituto Federal de Educação, Ciência e Tecnologia do Pará que foi inicialmente instalado em 2008 provisoriamente na Escola Municipal de Ensino Fundamental Jorge Ramos, situado no Bairro da Vila Sinhá, e atualmente em espaço próprio no Bairro da Vila Sinhá.

As atividades de extensão analisadas pela pesquisa foram desenvolvidas nas dependências do IFPA - Campus Bragança, em particular no Eco Espaço 'Dr. Edgar de Souza Cordeiro', que foi construído para servir como laboratório a céu aberto; com o intuito de trabalhar a educação ambiental de uma forma mais prática através do ensino e da extensão nos cursos superiores de Tecnologia em Gestão Ambiental, Tecnologia em Agroecologia, Técnico em Agropecuária e a comunidade em geral.

Durante o Dia Mundial da Água e a Semana da Árvore Amazônica, comemorados no final do mês de março, foram realizadas intervenções de caráter extensionista, o que ocorreu na Feira do Produtor Rural Familiar de Bragança (PA), como forma de sensibilizar os produtores e o público que frequenta a feira acerca dos problemas ambientais atuais e evidenciar as medidas mitigadoras possíveis. $O$ evento possibilitou um estreitamento entre a academia (alunos e professores) com o público que necessita de informações para criar uma percepção mais responsável sobre os problemas ambientais atuais.

\subsection{Sujeitos da Pesquisa}

O público alvo da pesquisa foram alunos do curso Superior de Tecnologia em Gestão Ambiental, os quais atuaram em algum projeto de extensão realizado pelo IFPA - Campus Bragança; e que tenham obtido, ou não, bolsa de assistência pelo projeto. Além dos alunos do curso, as pessoas que participaram das atividades, catadores de resíduos, alunos de escolas públicas e privadas, foram fundamentais para a execução das atividades e posterior avaliação das mesmas.

\subsection{Procedimentos Metodológicos}

Compreende as etapas de desenvolvimento da pesquisa e está dividido nos seguintes tópicos: coleta de dados, análise dos dados e análise de conteúdo.

\subsubsection{Coleta de dados}

A pesquisa e análise da bibliografia referente às temáticas: educação, educação no ensino superior, extensão acadêmica, projetos de extensão, entre outros, foram os documentos que substanciaram a conceituação, compreensão e aplicabilidade da extensão como forma de consolidação do ensino, promoção da prática da cidadania e superlativar a visão dos problemas locais, regionais e globais. De acordo com Freire (1979), o conhecimento não se refere apenas ao que está nos conteúdos dos livros didáticos, mas em tudo que se estabelece nas relações homem homem e homem - mundo. 
A este nível espontâneo, o homem ao aproximar-se da realidade faz simplesmente a experiência da realidade na qual ele está e procura. Esta tomada de consciência não é ainda a conscientização, porque esta consiste no desenvolvimento crítico da tomada de consciência. A conscientização implica, pois, que ultrapassemos a esfera espontânea de apreensão da realidade, para chegarmos a uma esfera crítica na qual a realidade se dá como objeto cognoscível e na qual o homem assume uma posição epistemológica. (FREIRE, 1980, p26)

Dessa forma, a conscientização implica não apenas na experiência prática, mas também do processo de compreensão da realidade com posterior desenvolvimento da habilidade crítica acerca da questão apresentada.

Foram também realizadas entrevistas junto aos alunos envolvidos diretamente com os projetos de extensão desenvolvidos pelo curso superior de tecnologia em gestão ambiental do IFPA Campus Bragança. $O$ instrumento das entrevistas foi um questionário com perguntas abertas.

\subsubsection{Análise dos dados}

A análise de conteúdo, enquanto metodologia de análise e estruturação de dados, pode ser conceituada como:

Um conjunto de técnicas de análise das comunicações visando obter, por procedimentos, sistemáticos e objetivos de descrição do conteúdo das mensagens, indicadores (quantitativos ou não) que permitam a inferência de conhecimentos relativos às condições de produção/recepção (variáveis inferidas) destas mensagens (BARDIN, 1977, p. 42).

$\mathrm{Na}$ análise de conteúdo, numa perspectiva qualitativa, o sujeito passa a ser o foco da pesquisa a partir de suas vivências e percepções sobre determinado fenômeno e/ou objeto. Nesse sentido, o "texto" e suas mais diversas dimensões passam a ser a expressão-mor do sujeito, cujo pesquisador / analista se debruça para investigar.

Nesse sentido, Moraes (1999) apresenta quatro fases distintas para cumprir a análise de conteúdo, quando envolve, além do texto, atividades de campo:

I. Unitarização, que se resume na transcrição e leitura das entrevistas com o objetivo de captar as unidades de análise (temáticas), que são pistas-chaves de conteúdo, que ajudarão na construção das categorias de análise;

II. Categorização, que consiste na reunião dos dados por afinidade ou semelhança com o objetivo de formar categorias temáticas;

III. Descrição, que se trata da explanação dos resultados encontrados na pesquisa de campo; e 
IV. Interpretação, que seria a reflexão e compreensão dos dados descritos por meio do confronto com o conhecimento científico.

A etapa de unitarização foi realizada a partir de uma primeira leitura dos questionários e da organização dos mesmos, por meio de numeração dos arquivos. A segunda etapa, de categorização, iniciou com uma leitura mais criteriosa das respostas com o intuito de definir as unidades de registro (para cada uma das perguntas do questionário) através da seleção de temas e conjuntos de palavras, conforme Quadro 1.

\begin{tabular}{|c|c|}
\hline to & rras \\
\hline $\begin{array}{l}\text { Quais os benefícios que as } \\
\text { atividades de extensão } \\
\text { universitária desenvolvidas } \\
\text { no seu curso proporcionam } \\
\text { para a sua formação? }\end{array}$ & $\begin{array}{l}\text { Aquisição de conhecimento: aprofundamento do assunto proposto / } \\
\text { complemento curricular / novos conhecimentos / possibilidades de se } \\
\text { especializar } \\
\text { Complementação educacional: levar as informações para além das } \\
\text { limitações institucionais / dentro de sala de aula não podem me } \\
\text { proporcionar. } \\
\text { Vivência prática: aguçar minha visão e postura diante dos dilemas / } \\
\text { entendimento sobre uma área de trabalho / me incentiva a buscar } \\
\text { melhorias. }\end{array}$ \\
\hline $\begin{array}{l}\text { que as atividades de } \\
\text { extensão universitária } \\
\text { desenvolvidas no seu curso } \\
\text { proporcionam para a sua }\end{array}$ & $\begin{array}{l}\text { ia de pontos negativos: Não existe ponto negativo nas atividades de } \\
\text { o / Não vejo pontos negativos / só tem a contribuir para a formação } \\
\text { o } \\
\text { ibilidade: Atividades que são pouco divulgadas }\end{array}$ \\
\hline $\begin{array}{l}\text { Quais os pontos positivos } \\
\text { no desenvolvimento de } \\
\text { atividades de extensão } \\
\text { universitária para sua } \\
\text { instituição? }\end{array}$ & $\begin{array}{l}\text { Acesso à comunidade: disseminação da formação e informação, não } \\
\text { somente para aqueles que estudam na instituição / abre portas para se } \\
\text { conhecer a instituição e os próprios alunos } \\
\text { Envolvimento dos alunos: desenvolver novos interesses nos alunos da } \\
\text { instituição / conhecimentos e a valorização / colocar em prática algumas } \\
\text { temáticas vistas em sala de aula. }\end{array}$ \\
\hline $\begin{array}{l}\text { no desenvolvimento de } \\
\text { atividades de extensão } \\
\text { universitária para sua } \\
\text { instituição? }\end{array}$ & $\begin{array}{l}\text { usência de pontos negativos: A instituição tem mais a ganhar qu } \\
\text { esvalorização: Infelizmente não tão valorizada pelos discente } \\
\text { centes / Falta de interesse por parte de alguns alunos / }\end{array}$ \\
\hline $\begin{array}{l}\text { Quais os pontos positivos } \\
\text { no desenvolvimento de } \\
\text { atividades de extensão } \\
\text { universitária para a } \\
\text { sociedade? }\end{array}$ & lade ta \\
\hline $\begin{array}{l}\text { Quais os pontos nega } \\
\text { no desenvolvimento } \\
\text { atividades de exte } \\
\text { universitária para } \\
\text { sociedade? }\end{array}$ & $\begin{array}{l}\text { ntos negativos: desconheço / só serão vistos a partir do } \\
\text { Im projeto de extensão for realizado de forma interna } \\
\text { s vezes não são bem aceitos pela sociedade }\end{array}$ \\
\hline
\end{tabular}

Quadro 1: Definição dos temas da análise. 
Posteriormente, na etapa de descrição, foram expostas as respostas obtidas junto aos discentes. Esses resultados foram descritos na forma de texto, buscando ao mesmo tempo discutir e compreender a visão dos entrevistados acerca da temática proposta. Nesse sentido, a interpretação das respostas considerou não apenas o pensamento do aluno sobre a temática, mas a vivência dos pesquisadores em projetos de extensão e o conhecimento científico proporcionado pelas referências bibliográficas.

Nesse sentido, foram feitas análises qualitativas com vistas a identificar e discutir os pontos positivos e negativos da utilização de atividades de extensão como ferramenta para a aprendizagem no ensino superior. No caso da pesquisa qualitativa, conforme explica Teixeira (2010, p. 137), “[...] procura-se reduzir a distância entre a teoria e os dados, entre o contexto e a ação, usando a lógica da análise fenomenológica, isto é, da compreensão dos fenômenos pela sua descrição e interpretação".

Nesse sentido, buscou-se desenvolver a análise a partir da compilação das informações obtidas através das pesquisas bibliográficas, legislação e junto aos discentes do Curso Superior de Tecnologia em Gestão Ambiental, considerando a história da extensão no contexto da universidade.

\section{A EXTENSÃO NO IFPA}

Toda instituição de ensino superior tem como pilares para a boa formação dos discentes de todo e qualquer curso a simbiose entre ensino, pesquisa e extensão. Contudo, não é o que se observa na prática. O ensino tende a ser sempre o carro-chefe da instituição, a pesquisa em segundo lugar, pois, trás visibilidade e status, e por último fica a extensão que geralmente não conta com os recursos necessários para o desenvolvimento das atividades e consequentemente conta menos interesse por parte de docentes e discentes.

Poucas são as ações de extensão nas instituiç̧̃es, e as que são implementadas muitas vezes nem podem ser consideradas como atividades de extensão, uma vez que o conceito de extensão universitária ainda é compreendido pela maioria dos alunos apenas do ponto de vista acadêmico.

Este contexto não é diferente no Instituto Federal de Educação, Ciência e Tecnologia do Pará - IFPA, ainda mais por ser uma instituição nova, mas de alma madura, que nasceu da educação profissional tecnológica atendendo inicialmente ao pós-médio e que atualmente mergulha no ensino superior e pós-graduações (TAVARES, 2012). O IFPA foi criado em 29 de dezembro 2008 pela Lei Federal № 11.892/2008 que regulamenta a Rede Federal de Educação Profissional, Científica e Tecnológica; e somente a partir Resolução N 174/2017-CONSUP DE 25 DE ABRIL DE 2017, que foi regulamentada a extensão no instituto, ou seja, levou mais de seis anos para o reconhecimento da importância desta vertente do processo educativo. Enquanto isso, ensino e pesquisa caminhavam e ainda caminham, mas, a extensão continua rumo ao desconhecido mesmo com a promulgação da normativa. No IFPA campus Bragança não é diferente, somente a partir da segunda gestão e com a criação da coordenação de extensão foi que ocorreu um salto no desenvolvimento de projetos e atividades voltados para a comunidade externa. 
Este salto ocorreu de forma mais notória no ano de 2016 com o início de quatro projetos voluntários de extensão voltados para os cursos superiores de Física, Agroecologia e Gestão Ambiental; no mesmo ano, com a abertura do edital do Conselho Nacional de Desenvolvimento Científico e Tecnológico - CNPQ, dois projetos foram aprovados para serem contemplados com um bolsista cada; já no ano de 2017, com o edital interno do IFPA Campus Bragança, dez projetos foram aprovados no campus para serem contemplados com um bolsista cada, no qual três destes estavam diretamente relacionados ao curso superior de tecnologia em gestão ambiental, conforme se observa no Quadro 2.

\begin{tabular}{|l|l|}
\hline \multicolumn{1}{|c|}{ Cursos envolvidos } & \multicolumn{1}{c|}{ Local } \\
\hline Licenciatura em Física & $\begin{array}{l}\text { O uso da experimentação utilizando materiais alternativos como } \\
\text { mediador/incentivador no ensino e aprendizagem da física. }\end{array}$ \\
\hline Agroecologia & $\begin{array}{l}\text { Reaproveitamento de resíduos orgânicos em escola primária do município } \\
\text { de Bragança - Pará. }\end{array}$ \\
\hline Licenciatura em Física & $\begin{array}{l}\text { Física moderna com uma abordagem didática para a aprendizagem } \\
\text { significativa }\end{array}$ \\
\hline Gestão Ambiental & Gestão de resíduos sólidos e a educação ambiental no ensino fundamental \\
\hline Gestão Ambiental & Vivência ambiental no Eco Espaço - Dr. Edigar de Souza Cordeiro \\
\hline Agroecologia & $\begin{array}{l}\text { Disseminação de métodos de produção de biofertilizantes apropriados } \\
\text { para condições edáficas em propriedades de agricultura familiar na região } \\
\text { de Bragança - PA }\end{array}$ \\
\hline Licenciatura em Física & Educafísica: além da equação \\
\hline Gestão Ambiental & Reciclando e aprendendo \\
\hline Agroecologia & $\begin{array}{l}\text { Avaliação dos parâmetros de cultivo e implantação de um sistema de } \\
\text { aquaponia para a produção consorciada de tomate cereja (lycopersicon } \\
\text { esculentum var. Cerasiforme) e tambaqui (colossoma macropomum) na } \\
\text { comunidade do vila verde, Bragança-Pará }\end{array}$ \\
\hline Agroecologia & $\begin{array}{l}\text { Ensino da produção de biofertilizantes líquidos para comunidades rurais na } \\
\text { região bragantina }\end{array}$ \\
\hline
\end{tabular}

Quadro 2: Projetos de extensão aprovados em edital interno do IFPA - Bragança no ano de 2017.

Nos anos de 2018 e 2019 não foram aprovados projetos de extensão junto ao curso superior de Gestão Ambiental. Entretanto, o projeto do Eco Espaço prosseguiu com a aplicação de atividades extensionistas junto à comunidade e com o apoio voluntário dos alunos dos cursos Superiores de Tecnologia em Gestão Ambiental e Agroecologia, e Técnico em Agropecuária.

\subsection{A extensão na prática discente do curso superior de tecnologia em gestão ambiental}

O curso superior de tecnologia em gestão ambiental no Campus Bragança-PA iniciou as atividades do curso com a primeira turma no ano de 2011. Do início do curso até o ano de 2016, nenhum projeto de extensão havia sido registrado junto à coordenação de Gestão Ambiental ou a coordenação de extensão.

Em 2016, surgiu o primeiro projeto diretamente vinculado ao curso de gestão ambiental, o qual teve como foco a gestão dos resíduos sólidos. No projeto em questão foram desenvolvidas 
atividades de sensibilização junto à sociedade, oficinas de reciclagem, e parcerias junto a catadores de resíduos. Este primeiro projeto contou com a participação de 4 professores e um total de 12 alunos que atuaram diretamente na produção de materiais, produção de textos, planejamento das intervenções e sensibilização junto a comunidade. Entretanto, não contava com nenhum tipo de auxílio financeiro, fator que limitou o desenvolvimento das atividades.

Este projeto de extensão deu origem a outros 3 projetos: 1) Gestão de Resíduos Sólidos e a Educação Ambiental no Ensino Fundamental; 2) Reciclando e Aprendendo; e 3) Eco Espaço. 0 primeiro buscou levar para as escolas, através da educação ambiental, discussões e práticas acerca do correto gerenciamento dos resíduos, e para isso utilizou atividades lúdicas e materiais reaproveitados para levar a discussão até os alunos (Figura 1); o segundo objetivou dialogar e ensinar técnicas de reciclagem de materiais para a comunidade em geral, mas com foco para os catadores de resíduos recicláveis, os quais puderam participar de oficina de reciclagem de óleo de cozinha para a produção de sabão (Figura 2); e o terceiro procurou desenvolver práticas de produção vegetal a partir do reuso de embalagens de garrafa pet, tetrapack, pneus e embalagens em geral (Figura 3).
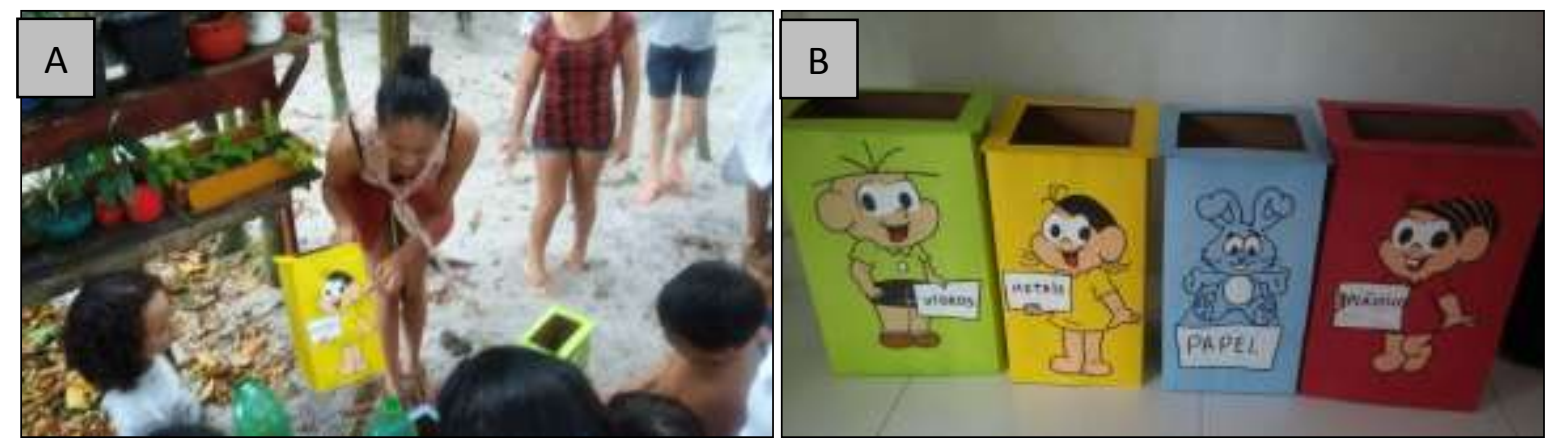

Figura 1: A) Projeto Educação Ambiental no Ensino Fundamental; B) lixeiras confeccionadas para a atividade.
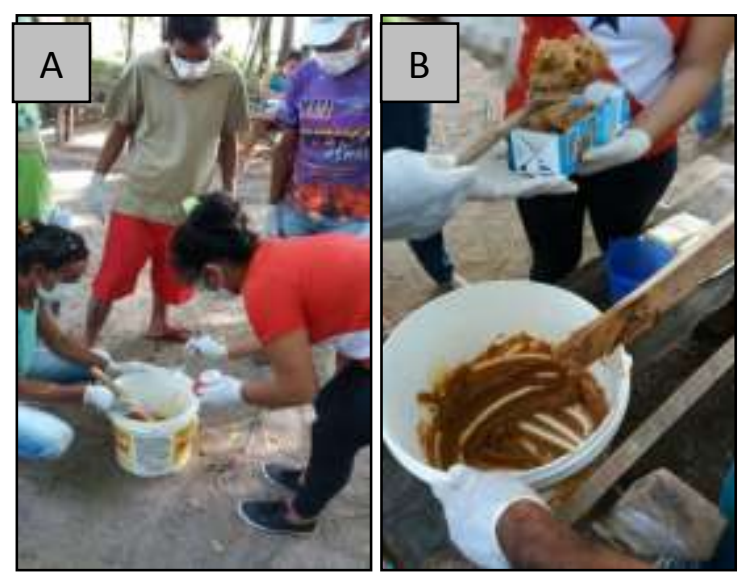

Figura 2: Oficina de produção de sabão a partir de óleo de cozinha - (A) etapa inicial de produção; (B) etapa final da produção. 

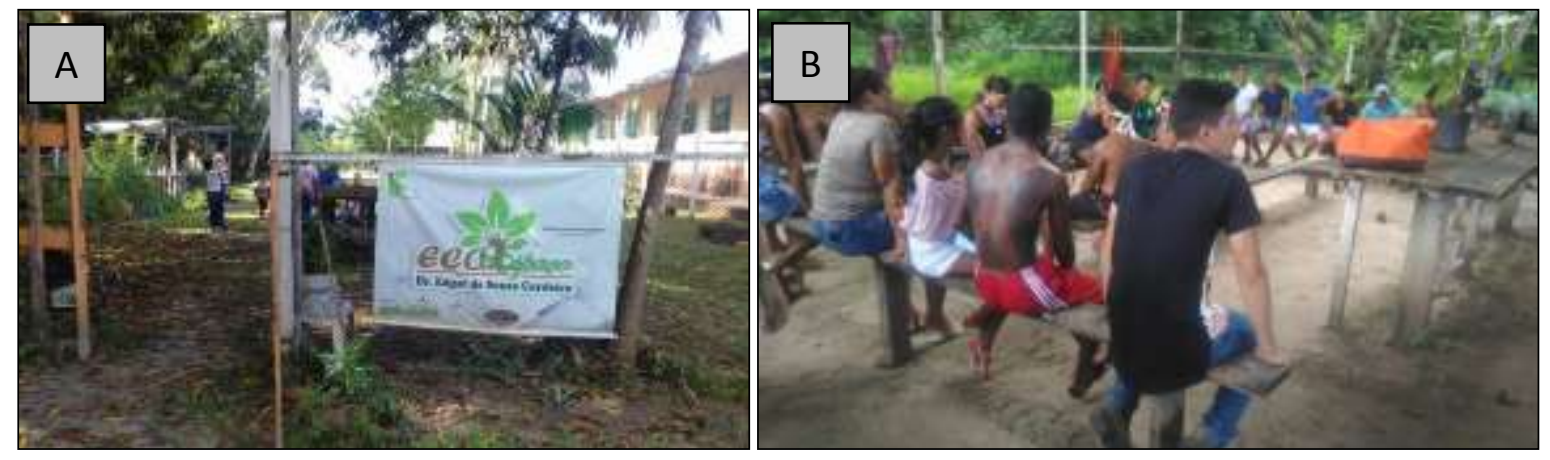

Figura 3: A) Eco Espaço; B) Oficina de produção vegetal.

Esses três projetos de extensão foram aprovados em edital interno do IFPA e contavam, cada um, com um aluno bolsista. Os alunos bolsistas eram os responsáveis diretos pela execução dos projetos, mas contavam sempre com o auxílio de alunos voluntários, dos cursos superiores de Gestão Ambiental e Agroecologia, que participavam das atividades, coletavam e produziam material para a realização das mesmas.

\subsection{Entraves para o desenvolvimento de atividades de extensão no IFPA - Bragança.}

A Extensão no IFPA Bragança, ainda em processo de estruturação, incorre no dilema de incutir na gestão do Campus como na visão dos docentes em geral a necessidade de realizá-la como resultado final do processo de formação de cada etapa dos discentes das diversas áreas de ensino do Campus.

A tarefa de concretizar a extensão vem sendo dinamizada pela recente instaurada Coordenação de Extensão que com empenho, mas com apoio limitado e pouco interesse da maioria dos docentes, vem estimulando e dando cobertura a alguns eventos casuais.

Estes eventos casuais, pontuais e esporádicos conseguem, gradativamente, possibilitar este complemento na formação discente, como também, possibilitar a visibilidade institucional. Entre os eventos caracterizados como atividades de extensão no Campus temos como exemplo aqueles realizados pelo curso superior de Tecnologia em Gestão Ambiental.

A semana da árvore amazônica realizada no ano de 2017 na feira do produtor rural contou com a participação dos cursos superiores de tecnologia em Gestão Ambiental e Agroecologia, bem como o curso técnico de pesca. Na ocasião foram apresentados trabalhos produzidos pelos alunos, bem como realizadas oficinas de reciclagem e sorteio de mudas (produzidas no Campus do IFPA) para os visitantes (Figura 4, A e B). 


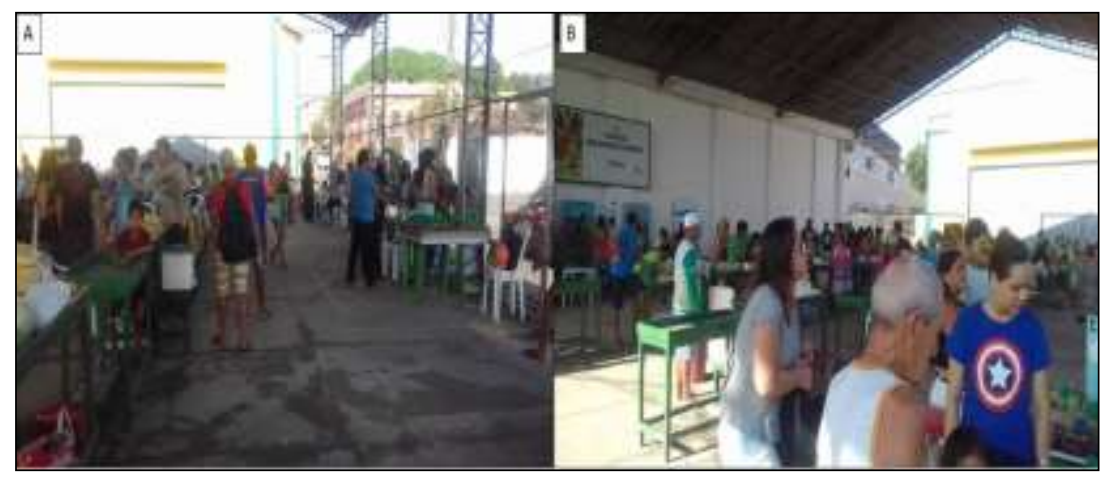

Figura 4: A) Feira do produtor rural de Bragança e a apresentação de trabalhos acadêmicos dos alunos do IFPABragança. B) Panorama da visitação e participação da comunidade no evento.

A semana do meio ambiente, realizada nas dependências do IFPA no ano de 2017 contou com a participação de alunos dos cursos Superiores de Tecnologia em Gestão Ambiental e Agroecologia, Técnicos de Pesca e Eventos. Na ocasião foram ofertados mini-cursos e oficinas voltados para a temática ambiental, bem como realizadas exposições dos trabalhos desenvolvidos pelos alunos (Figura 5, A, B e C).

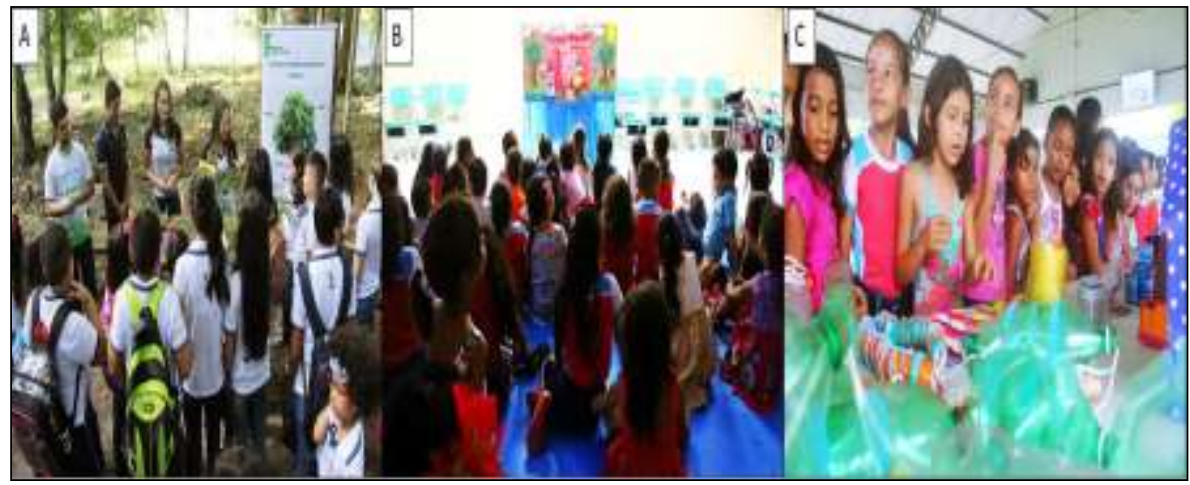

Figura 5: A) Trabalho apresentado sobre as árvores amazônicas; B) Apresentação de teatro de fantoches com temática ambiental; C) exposição de brinquedos construídos com material reciclável.

Estes eventos para serem realizados contam com a colaboração dos organizadores em relação à criatividade e em adequações das necessidades, principalmente no que se refere a recursos financeiros. Os recursos destinados a fomentar a extensão dentro do IFPA - Bragança são irrisórios ou inacessíveis, pois necessitam de um cabedal burocrático e tempo para encaminhamento processual, o que acaba impossibilitando a realização do evento e comprometendo a prática da extensão.

Para tentar superar os entraves, os professores, juntamente com a gestão do Campus, muitas vezes utilizam recurso próprio para levar adiante as atividades propostas. Percebe-se com isso que as atividades de extensão não têm recebido a atenção que merecem enquanto parte do processo de ensino e aprendizagem. Dessa forma, observa-se a necessidade, mesmo com as adversidades, de manter o foco para o fortalecimento das poucas iniciativas de extensão acadêmica 
já propostas no Campus, com vistas a sensibilizar docentes a criarem projetos de cunho extensionista e motivar discentes a participarem dos mesmos.

\subsection{O olhar dos discentes sobre a extensão no IFPA - Bragança}

A percepção dos discentes acerca das atividades desenvolvidas na instituição é de fundamental importância para a compreensão das demandas dos mesmos, bem como para a adequação das propostas educacionais da instituição.

Desta forma, no que se refere à visão dos alunos do IFPA - Bragança, as atividades de extensão são fundamentais para a formação de um bom profissional, pois possibilitam a complementação do aprendizado através do contato com situações práticas. Ademais, permitem que o aluno desenvolva habilidades específicas voltadas para a área de atuação da atividade de extensão. Por outro lado, os discentes percebem que existem entraves na execução dos projetos desenvolvidos no curso, que limitam as possibilidades de aprendizado, e destacam como um dos principais problemas a falta de divulgação e a limitação financeira, por parte da instituição, para desenvolver as atividades junto à sociedade.

No que diz respeito aos benefícios para a instituição, os discentes notam que através dos projetos de extensão é possível atrair o interesse de novos alunos. Ao desenvolver atividades de extensão junto às comunidades, é possível atrair o interesse de pessoas que veem nestas intervenções uma alternativa para a melhoria da qualidade de vida, ou mesmo a solução para alguns problemas do quotidiano.

Dessa forma, novos alunos podem ser estimulados a buscar na academia uma forma de proporcionar, para a sua própria comunidade, as melhorias necessárias. Entretanto, em função da ausência ou limitação de recursos financeiros, da disponibilidade de tempo para a execução dos projetos e, em algumas situações, o descaso de docentes e alunos impossibilitam a conclusão das atividades e consequente alcance dos objetivos da extensão. Nesse cenário, a instituição perde credibilidade junto à sociedade e até mesmo junto aos discentes.

Nesse sentido, vale ressaltar o quanto a atividade extensionista é importante na formação do acadêmico e pode contribuir na aquisição de experiências que possibilitam a ampliação da compreensão em relação às atribuições profissionais. Através do desenvolvimento de atividades de extensão o aluno tem a possibilidade de colocar em prática o conteúdo aprendido em sala de aula, retornando à sala de aula através da pesquisa realizada dentro da própria atividade extensionista, fechando o ciclo da tríade Ensino-Pesquisa-Extensão tendo como foco a realidade nua e crua.

Observa-se, então, a importância que os projetos e atividades de extensão representam para a formação acadêmica em nível superior, tanto pela função social que exerce ao levar o conhecimento para além dos muros institucionais; como também pela possibilidade de ser utilizada como uma ferramenta para aproximar a teoria e a prática. Ademais, permite que os acadêmicos sejam expostos ao contato direto com a sociedade e absorvam o conhecimento e as contribuições que esta tem para oferecer à academia. 


\section{CONSIDERAÇÕES PARA AMPLIAR O DEBATE}

A extensão é fruto de uma história que prioriza o ensino e a pesquisa nas instituições de ensino superior, e que demanda mais atenção e investimentos por parte da gestão. A partir da análise torna-se evidente a importância das atividades de extensão para a formação dos alunos de cursos superiores, uma vez que aproxima a universidade da sociedade, possibilitando que o discente, ainda na graduação, seja capaz de colocar em prática o que foi assimilado em sala de aula.

A extensão acadêmica, embora com diversas limitações, conforme discutido neste artigo, consegue contribuir para a formação profissional dos alunos do curso superior de tecnologia em gestão ambiental. É notória a necessidade de maiores investimentos, principalmente financeiros, para o desenvolvimento das atividades de extensão. Porém, não apenas com a finalidade de formar profissionais mais capacitados, mas também com o objetivo de aproximar a instituição da sociedade e instigar novos alunos a buscar na academia o conhecimento necessário para desenvolver projetos sociais e ambientais que as comunidades anseiam.

A extensão como consolidação da práxis do conhecimento na formação do discente e docente de ensino superior é de extrema importância para a criação de campos férteis de onde emergirão novos conhecimentos, sinergia de saberes, tecnologias inovadoras, pesquisas de ponta, como também propiciará uma humanização dos envolvidos, o que permitirá por parte das instituições de ensino cumprir com seu papel social e nas transformações das realidades locais.

\section{REFERÊNCIAS}

Bardin, L. (1977). Análise de conteúdo. Lisboa: Edições 70.

Brasil. (2008). Lei Federal no11.892. Acesso em 30 de outubro de 2017, disponível em <http://www.planalto.gov.br/ccivil_03/_ato2007-2010/2008/lei/l11892.htm>

Brasil. (25 de abril de 2017). Resolução no174/2017 - CONSUP. Acesso em 30 de outubro de 2017, disponível em <http://proex.ifpa.edu.br/2015-10-05-03-55-12/resolucoes/1277-resolucaon-174-2017-consup-de-25-de-abril-de-2017-fundamentos-os-principios-e-as-diretrizespara-as-atividades-de-extensao>

Chiminazzo, M. A., Vieira, L. P., Pereira, D. A., Andrade, R. S., Jorge, T. B., \& Junior, W. G. (jan-abr de 2018). Expedição IFSULDEMINAS: Valorizando as características socioambientais locais na extensão. Revista Brasileira de Extensão Universitária, 9(1), 57-64.

Engel, G. I. (2000). Pesquisa-ação. Educar, 181-191.

Freire, P. (1979). Extensão ou comunicação? Rio de Janeiro (4 ed.). Rio de Janeiro: Paz e Terra.

Freire, P. (1980). Conscientização: teoria e prática da libertação. São Paulo: Moraes.

Freire, P. (2018). Extensão ou comunicação? (19 ed.). Rio de Janeiro/São Paulo: Paz e Terra. 
Jezine, E. (12 a 15 de setembro de 2004). As práticas curriculares e a extensão universitária. Anais do 2 o Congresso Brasileiro de Extensão Universitária. Belo Horizonte.

Mendonça, I. B., Santos, B. A., Silva, L. B., Dantas, A. C., Santos, A. P., Barros, C. C., . . Costa, C. L. (março de 2013). Extensão universitária em parceria com a universidade. Cadernos de Graduação, 1, 149-155.

Moisés Felix de Carvalho Neto, C. M. (2018). Extensão universitária e aproximação dialógica: a experiência do projeto escola no campus no sertão de Pernambuco - Brasil. Extramuros revista de extensão da UNIVASF, 6, 111-124.

Moita, F. M., \& Andrade, F. C. (maio/agosto de 2009). Ensino-pesquisa-extensão: um exercício de indissociabilidade na pós-graduação. Revista Brasileira de Educação, 14, 269-280.

Moraes, R. (1999). Análise de Conteúdo. Revista Educação, 22, 7-32.

Nogueira, M. d. (2005). Políticas de extensão universitária brasileira. Belo Horizonte: Editora UFMG.

Paula, J. A. (2013). A extensão universitária: história, conceito e propostas. Interfaces - Revista de Extensão, 1, 5-23.

Rodrigues, A. L., Prata, M. S., Batalha, T. B., Costa, C. L., \& Neto, I. d. (março de 2013). Contribuição da extensão universitária na sociedade. Cadernos de Graduação, 1, 141-148.

Tavares, M. G. (2012). Evolução da rede federal de educação profissional e tecnológica: as etapas históricas da educação profissional no Brasil. IX ANPED SUL - Seminário de Pesquisa em Educação da Região Sul, 1-21.

Teixeira, E. (2010). As três metodologias: acadêmica, da ciência e da pesquisa (7 ed.). Petrópolis: Vozes.

Tripp, D. (setembro-dezembro de 2005). Pesquisa-ação: uma introdução metodológica. Educação e Pesquisa, 31, 443-466. 